\title{
Kinship with Reptile: New Meaning of Kinship in Family Reptile Lovers
}

\author{
Erwan Baharudin ${ }^{1}$, Ernawati $^{2}$ \\ erwan.baharudin@esaunggul.ac.id ${ }^{1}$, ernawati@esaunggul.ac.id
}

Faculty of Communication Universitas Esa Unggul, Jalan Arjuna Utara No. 9, Tol Tomang, Kebun Jeruk, Jakarta Indonesia ${ }^{1}$, Faculty of Law, Universitas Esa Unggul, Jalan Arjuna Utara No. 9, Tol Tomang, Kebun Jeruk, Jakarta Indonesia ${ }^{2}$

\begin{abstract}
Human animals relationships from time to time change. At the time of hunting and gathering, animals are seen as a source of food and clothing, but when humans successfully domesticate animals, gradually they are used as pets. The animals most commonly used as pets are dogs, cats and birds. The purpose of this study is to describe the social-cultural aspects of human relationships with animals over time, analyzing the dynamics of change that underlies the integration and role of reptile in the household and contextualize the new meaning of kinship multispecies. This research is a qualitative research using ethnography in family of reptile lovers. The results of this study indicate a change in the way of view of reptiles that have a creepy image in the community. These reptile lovers' families have their own way of negotiating when dealing with law enforcement, associated with their reptiles protected by law. The conclusion of this study is that the intense interaction between humans and reptiles has caused deep emotional attachment to create a new meaning in reptile lovers' families that reptiles are not limited to pets, but have been regarded as human relatives.
\end{abstract}

Keywords: reptile myth, human reptile interaction, kinship

\section{Introduction}

Humans with animals have long interacted, began to be used as food and clothing, animals were then taken up, as religious ritual beliefs, totems, symbols, games, offerings, therapies, as pets, in other words animals are an integral part centered on human [1]. Thus with the existence of animal domestication, they are no longer the attention of animal experts, medicine, and biology alone, but has become the focus of social science because there is a cultural element in it. With regard to the animal myth, certain types of society have stories that some people believe to be true. Reptiles in society are animals full of mystical elements.

One of the beliefs of this mythical or mythical reptile is that Asram and Aminah and their six children living in Pare-Pare, South Sulawesi, live together with a crocodile. The crocodile is already considered like his own family. Crocodile with a length of 1.5 meters and weight of 70 kilo gram, named Puang Nene. Aminah was convinced that the reptile beast was the twinning of Aminah's father Ambo Siru. The crocodile is given a pond in his bedroom. Even to eat sometimes this crocodile is fed by Aminah. The story about animals is also delivered by Rahman, 52 years old who works as vice dean of a private university, he told me that in his village in Sumatra there is a large black snake that lives in the forest. Because it's so big, the snake is not as nimble as the little snakes that like to roam around, it just moves occasionally 
and when it preys on wild boars, deer, or humans it just sucks its prey. When prey, the distance between the snake and its target is about one meter. Already many villagers are missing and believed to be eaten by the snake. In addition, if we dream of a snake with dark color, then we will experience misfortune, while if the snake is white, then we will get luck.

The story of the reptile image, especially snakes, is not only we hear directly when we are doing research, other creepy stories we've heard from our neighbors and friends while still in school, where the snake while nesting in one place and he was comfortable with his new place he can call his friends to come live in the new place, especially if the snake is dark, usually he is a devil incarnate serpent. Thus, when we meet the snake we have to ask directly with him "hi snake, if you serpent so-soon get away from our house". If the snake goes straight, it means that the serpent is true as a devil of the devil, but if it turns out the serpent remains silent, then we must immediately kill it for fear that the snake will harm the residents of the house.

Another story in the village Sumberejo in the city of Jember, here there is a belief that on the beach Watu Wulo, there is one stone long into the middle of the beach, said he said the stone is a giant snake. The giant snake feeds on all the animals that live in the village, so people in the village can not eat animals because they are gone. Then there are 2 young men who dare to challenge the giant snake and finally the snake can be killed by cutting his body into three. One of these pieces is now called Watu Wulo, while the other two snake body parts are now in the city of Banyuwangi and Pacitan.

The story of the myth of snakes is also found in Bima Nusa Tenggara, where there is a small island inhabited by many black and white snakes. The myth of the snake is that they were once a human being at war, but they lost and the ship was drowned near the island. The locals believe that the snakes are the guardians of his village who bring blessings to the local people, if any man who came on the snake island and brought a black and white snake tail will be a disaster in their village, therefore, the citizens there is very keep the existence of the snakes. Meanwhile, in the Java region has a strong mythology about the existence of a character named Nyai Roro Kidul depicted with the form of a snake that can change into a beautiful woman. This Nyi Roro Kidul can give a wealth to the man who asked for it and instead he can take the life of anyone whom he wants based on the agreement between the man who asks for his help.

Research on the bond between humans and animals has been studied in various disciplines such as psychology, medicine, biology, and others. But in the realm of anthropology is still not much studied, although actually anthropology has long been interested in the relationship between animals in culture [2]. Research on the bonds of humans and animals one of them done by the psychologist LoBue \& DeLoache in 2008, the results of his research mentions that from the existing animals, snakes are the animals most feared by humans, both outwardly and after he was born. The fact that the fear of snakes is the result of human evolution as part of a mammal. They use a 1-2 year-old baby subject that shows the snake through video and pictures and compares it to other animals through the same method. The result is that the baby reduces the intensity of seeing snake impressions when compared to other animals such as giraffes. Of course it is hard to accept that this reaction is a form of fear. But please note that the subject is a baby who has more limited behavior when compared with adult humans including fear behavior. In general, the results of this study confirmed that the fear of snakes is a human innate instinct as a mammal [3].

Similarly, studies conducted by Prokop, Ozel, \& Uşakc, that women turned out to have a higher level of fear of snakes when compared with men. This is due to the belief in women that he is less able to deal with situations that endanger him, one of which is a physical weakness. In addition women also believe more in the negative myths about snakes. The second finding is that students from biology departments have a lower level of fear when compared to students 
from other departments. This is due to his knowledge of living things including a more realistic and logical snake. A third finding is that students with pets have a lower fear of snakes than college students who do not take pets. This is because raising animals will make people knowledgeable about the characteristics of animals, increase the intensity of the relationship of something related to nature, and cultivate feelings of empathy. And the last result of this study is that the fear of snakes is also influenced by the extent to which insight, knowledge and myths he believes about snakes [4]. This attitude towards animals is different between those who have never had a pet and who already have pets. The same thing is also found that snakes that have a frightening image, but it is amazing for some humans. Scary because the snake here becomes part of the devil, as in the myths that developed in some countries. The last discovery of the field of psychology to human relations with animals says that people who have close relationships with pets have a positive impact, self-confidence, care, and empathy are high [5].

\section{The Changes of Social Culture}

Increasingly modern, the image of the animals began to change its function, starting as the fulfillment of the needs of human primary life to the pets. Animals previously unthinkable to live with humans such as snakes, crocodiles, and now have begun to be used as pets at home. The most favorite dogs in America at this time number one are the dogs, second are cats and the third are birds [6], Meanwhile in the UK, the dog became a favorite of choice first, followed by a cat and followed by fish [7]. A survey conducted by the Harris Interactive 1 in 2012 online about pets, found that three out of five Americans now have pets. It seems that in an advanced country, having a pet is a fulfillment of its own needs. The owners of these pets vary, ranging from children, adolescents, adults to the elderly who have their respective status. The way of ownership of these animals varies, some are adopted through pet shops, captive breeding, friendship, through other animal provider institutions. The owners of these animals consider this pet has a charm like funny, exotic, luxurious, so it can cause affection just like humans [6].

Some people also see animals as subjects that must be protected, because their existence is regarded as a threat to humans, and also hunted because it can be used economically. For example, like dogs, for some Muslims, their presence in the surrounding environment The studies of human relationships with animals today mostly come from European countries, from Asia and the Middle East has not much of a study. However, if viewed from the culture of raising animals, Indonesia has started doing a lot of it. This can be seen the emergence of some pet stores and animal lovers community that emerged, as well as a few animal contests held. If the types of animals that are commonly used as pets are dogs, cats, birds and fish [6], then animals that still have a scary image, filled with myths and magical beliefs have also begun to be made into several options as pets, such as snakes, lizards and crocodiles. This trend is marked by the presence of those who keep reptiles, and also the emergence of reptile-loving communities. Animals as domestic pets have their respective roles, indicating the tendency of these pets to be an important part of humans and have a new direction that can not be separated in human life, as well as human interaction with other humans or even as relatives. The relationship between humans and animals is an interesting and important topic for cultural studies, because from time to time, the use of animals in human life is always changing according to culture and environment. With the exception of reptiles, the myth of the reptiles has gradually begun to shift away from the creepy and dangerous animals into tame animals and can be used as domesticated pets, just like any other animal that has been used as a pet. However, not many people can think neutrally against snakes. Snake is an animal that has a strong link in humans, which on one side of the snake is a fascinating animal on the other is very frightening [8]. However, today the number of reptile keepers is increasing. This can be 
seen from the increasing number of reptile lovers community from year to year is always increasing. This can be seen from events that are done by them such as reptile contests, reptile exhibits, and reptile education to the public by reptile keepers [9].

\section{Problems}

Kinship is initially genealogical in nature where this bond is obtained from marriage and offspring. Gradually, this kinship is regarded as a symbol that no longer considers kinship acquired only to the extent of marriage and offspring only [10], but more emphasize kinship on the relationship or social and emotional interaction [11]. Animals are an integral part of human culture since ancient times. They are used by humans as foodstuffs, materials for testing, therapy, up to use in the field of sports. Interaction is gradually becoming more intimate again that makes some animals as a pet at home. Some research in Europe says that pet owner now perceives his pet as a friend, and part of the family [6].

Seeing the shifting meaning of his pet in some of the current studies, in which people build kinship ties with their pets, we will conduct research and observations on three families who have reptile pets from how they initially made their pet choices, and how they learned about reptiles, their interaction, until then proceeds in perceiving the role of the reptile in their family. We chose this reptile animal to complete the study of pets that have not been discussed by many researchers, because the most popular in the breeding is dogs and cats. While Reptile, which in socio cultural society of Indonesia have image and story full of myth, so to be used as a pet has been difficult, let alone to be recognized as a member of the family. Theoretically, our writing will contextualize the new meaning of kinship through a new formation in multi species homes.

\section{Research Purpose}

We do this research to explain the social aspects of human culture with animals, to explain and analyze the underlying meaning of reptile integration into the household and to contextualize the new meaning of multi-species kinship.

\section{Methodology}

Methodologically, the approach in this research is qualitative research. Therefore, this approach is intended to see, hear and understand directly the dynamics of the background of the integration and the role of reptiles as domestic animals in the household. This research covers field research and library research. The subject of our study consisted of three families that maintained reptiles namely Adi, Hari and Tarno family. The data collection in this research is by observation method involved, interview, and literature study.

\section{Results and Discussion}

\section{Animals as Family Members}

Recent studies of human relationships with animals in the context of family relations define pet culture change meaning when they are shaped as human beings like children, siblings of different people from families [12]. This animal is formed as a flexible person, in 
accordance with the owner's emotional commodity. Research on people living with dogs and cats in Israel, treated as pre child, semi child, child. This is an illustration that the kinship formed with animals is not static, is a fluid relationship and can change over time [2].

It is seen in the three informants that we studied the family Adi, family Hari, and family Tarno. When we were amongst the families of our informants, we often heard statements from Adi, Hari and Tarno that the reptiles in their homes were considered part of their own families, as were the other family members who also considered reptiles in their homes to be like their own families. Animal statements as part of the family also occur in some other countries such as the survey conducted by Harris polls in 2011 suggested that more than $90 \%$ of respondents think that the pets they care for are part of the family. Similarly, national surveys in Australia, of $88 \%$ of respondents who maintain their pets regard the pets as part of the household. This survey is based on a questionnaire filled by respondents and using the data quantitatively. In contrast to our research using qualitative methods, where we go directly to the field to see the interaction of owners with reptiles. The study conducted by Harris and our research all claim that the pets maintained by the owner are already regarded as members of his family as well as relatives.

Interactions made by humans with their reptiles, more physical interactions, because reptiles can become more characteristic when they are in direct contact with humans. However, because these reptiles tend to use heat and motion sensors, then for the type of snake and crocodile noisy-sound effect less. However, it does not mean that in interacting humans with reptiles do not use sound. Sometimes humans invite to play and feed often call the name given to their reptiles, and vice versa, crocodiles if they feel less comfortable with the interaction given, they produce sounds like people snore. Treatment of reptile keepers such as naming, feeding directly or feeding where the food is also a human food such as banana or chicken meat, giving toiletries, taking pictures with other members of the human family, and sharing food places in the same refrigerator is a the form of human relationships with animals, both of which have directly involved emotions in which reptiles who become pets are considered part of their family.

This also happened in the Adi family and the Hari family, as we were among them we met both Mr. Adi and Hari mentioning his reptile name when feeding, bathing and while relaxing. Even Mr. Adi when buying raw chicken meat, he shared to his crocodile nova, some for Mr. Adi and his family to eat. The same food to eat together also happens to Hari's family as when feeding on the panya with the bananas he buys for consumption together.

\section{Animals as Brothers and Children}

The interesting things we get in the field are the phrases in depicting reptiles like "he's like our son," "like a childish child," are often heard phrases when looking at the interactions between humans and their pets. The sentence is most often catapulted to reptiles of lizards when it is attached to the shoulders of its keepers. Likewise, when reptile lovers take their pets with them, they always take care of the physical and reptile comforts when traveling or when there is a danger lurking like time in the sun and then a cat approaches, then the family member who sees immediately expels the cat away from the reptile. This shows that the reptile is a helpless animal, just as a child is walking while in the vicinity of many motor vehicles that could have every second bumped into it. Therefore reptiles in less secure environments and when there are dangers lurk, then members of the human family then help them. Emotional ties to reptiles in families that have not had children can be used in early preparation exercises to have children, where care and love will be required [2]. Indeed, when 
we decide to keep animals, we must surely pay attention to the welfare of the animals, from feed, place, health, and also take the time to clean the cages, feed, and also interact with our play. These are the things that then gradually form our emotional bond with the pets are no longer animals, but as family members and children. Because it is considered a child, then the interaction that took place later is to take a walk around the house, while playing to your house and friends, cut his nails when it is long, go to recreation, and to the doctor when ill. After all they have lived with the human family, then all the necessities have been the responsibility of his pet owner, including the forms of communication, appreciation and caring for this animal. A form of affection for a reptile that is considered to be a child and treated the same as when in Mr. Adi and his family is away recreation to the ragunan, his son the Dodik brings with him the serpent. Likewise when the lizard who was named Silvi sick, he was taken to the vet.

\section{Animals as a Filler when the loneliness and Emptiness}

Many things that cause someone to experience loneliness, among others, left by other family members, move to a new residence, died by a spouse or the nearest person. It is then that triggers a person to be lonely. One way to deal with this loneliness is to have pets that can be invited to interact. Maintaining these animals can improve the quality of life [13].

In our study in the Tarno family, we noticed when the Princess was wanting to play and with her mother, but her mother had to leave for work so the princess had to be left behind. The loneliness of this Princess did not last long, because when lonely feel this Princess then play with the tortoise Sule named. Sule is regarded as his own brother, by playing with Sule and then his sadness and loneliness is gradually lost and the Princess becomes cheerful again. In interacting with this Sule, Princess lifts up and lets Sule walk in her hands, then in her stomach as she is occasionally placed on the floor then allowed to walk, said Princess she is running with Sule..

In addition to physically interacting, other interactions are also by talking, feeding, bathing and taking walks around the house. This is what Vhertesh said, that the change in human relationships with animals is not only physical, behavioral and emotional, but is manifested in the form of communication [2].

One of our research findings shows, compassion can make a person to fall in love with reptiles, and then from that pity comes the desire to nurture and care for reptiles. In the sense of compassion that indirectly humans interact with animals through phrases that imply a sense of human caring to the animal that was mentioned. As experienced by Anis, when seeing the Baron (a flower pygie) is thinner with mouth thrush, he then felt pity and then in front of Baron anis said at that time, hopefully you Baron get well soon. This form of communication interaction by speaking is one that is done by the keeper with his reptile.

\section{The Certification of Reptiles as the Possibility}

If human relationships with animals have been considered an interesting topic in the study of social science, but in anthropology, this interaction is still considered new in Indonesia. But now, human interaction with animals has become a trend, because it has begun many people who have pets in his home. At first this animal only as a game to be used as food and clothing, then shifted as a friend, and now it is considered as a family member. A kinship with animals is about recognizing the family relationship between humans and animals. Here there is a difference indeed, but it does not create a line of arbitrariness that gives human power to animals. This relationship is a good and positive relationship between humans and animals that are visible from the treatment of the animal. The interaction is based on a sense of respect, 
communication, empathy and concern for human and animal needs. Some research on human interaction with animals that ultimately led to a change in meaning that pets are as family members and relatives [6][2][14].

Several studies related to human-animal relations were conducted by Patricia K. Anderson in 2003, Nickie Charles and Charlotte Aull Davies in 2008, Dafna Shir-Vertesh in 2012, and Nickie Charles in 2014, revealing the findings that reveal that animals have occupying positions as part of family members and relatives. But the respondents in the above study, consisting of dog, cat, and rabbit keepers and exist in the United States, Britain and Israel. Our findings in Jakarta, no longer just dogs, cats and birds that can be used as pets, but reptiles also can be considered as pets and already considered as part of the family. This case is done by the family of Adi, Hari and Tarno.

In relation to research on human and animal relations, research on human relationships with parrots also exists where the results suggest that parrots can be considered as part of the family, one of which is the inclusion of emotions in keeping the bird [6]. The study was conducted in the United States using a review of literature and electronic surveys via the internet to parrot owners who want to know the role of parrots as pets. The bird keeper in this survey categorizes the bee as a friend, family member, and furry children [6].

We agree with these findings, because with deep emotional engagement there will be a quality relationship that can assume the animal as a relative. In these three families, it involves emotions such as spending time in caring, fearing and worrying about something when the reptiles do not eat and sick is a projection of empathy for their reptiles, with this emotional engagement, in the end they assume that the reptiles they keep are relatives. But we add again, because in our findings in the field besides deep emotions, the feeling of compassion is also the cause of someone finally regarded the pets as a relative.

\section{Conclusion}

The results of this study we can conclude that humans first see the animals from time to time change. Formerly considered a hunt for food, clothing, partners to hunt, guard shelter, until eventually used as pets. This is reinforced by Molly Mullin stating that anthropological studies in viewing human and animal interactions through the evolution of human and animal relations over time, and seeing different cultures around the world view the animal.

Studies conducted in previous studies say that the animals most often used as pets are dogs, cats, birds and fish because of its benign character and can co-exist with humans. However, with the change in human culture in viewing reptiles that were once known as dangerous and frightening wild animals, gradually began to change which today is much more used as pets such as snakes, lizards, monitor lizards and crocodiles.

This is in line with our findings in the field where our findings differ from research on human interactions with animals of the mammal and aves species. Reptiles in Indonesian society have mysterious myths and beliefs such as the incarnation of jinn and the bearer of misfortune and harm is already beginning to change. There are some families who choose to keep reptiles as pets because they can be benign and can coexist with humans as well as dogs, cats and birds. To be tame and invited to live side by side with humans, these reptiles have to be physically in touch with humans, because with that physical touch they will get used to connecting with humans.

Our second conclusion is that cultural change in maintaining reptiles as pets signifies a shift in beliefs about wild animals that can be domesticated as well as dogs and cats. This shift 
in trust is gained from the share of several individuals who are members of reptile lovers communities, which serve as shared knowledge. Similarly, the families we studied, in obtaining knowledge about reptile maintenance, joined the community of reptile lovers. The interaction with reptiles most often is physical contact, such as holding, bathing, taking walks, and talking. The emotion between family members and reptiles involves deep emotion in reptiles, so the reptile's role in reptile lovers' families, in viewing and interpreting their reptiles, is no longer a pet but begins to shift where reptiles are part of family or relatives. This is characterized by deep emotional engagement when interacting with the reptile.

Our third conclusion, a shift in the way of view of the animal occurs because of the quality of the interaction that is so close to cause human emotions to give or attach human character to the animal. It is this giving of human character that gives the animal meaning as a relative. These emotional qualities can be seen in the Adi, Hari and Tarno families when interacting with their reptiles such as naming humans on reptiles, playing games, bathing, bringing to the doctor when illness does not heal, talking to, and sometimes feeding by feeding it. Similarly, reptiles can provide a sense of comfort and joy to the maintainers, so that when the condition of the house was quiet, the owner of this reptile can interact with reptiles as a substitute for the sense of loneliness terseut. With the reciprocal relationship between humans and reptiles, and eventually switch roles from only reptiles as pets become relatives.

\section{References}

[1] N. Russell, "The Wild Side of Animal Domestication," Soc. Anim., vol. 10, no. 3, pp. 285-302, 2002.

[2] D. Shir-Vertesh, "Flexible Personhood': Loving Animals as Family Members in Israel," Am. Anthropol., vol. 114, no. 3, pp. 420-432, 2012.

[3] V. LoBue and J. S. DeLoache, "Detecting the snake in the grass: Attention to fearrelevant stimuli by adults and young children: Research article," Psychol. Sci., vol. 19, no. 3, pp. 284-289, 2008.

[4] P. Prokop, M. Özel, and M. Uşak, "Cross-cultural comparison of student attitudes toward snakes,” Soc. Anim., vol. 17, no. 3, pp. 224-240, 2009.

[5] M. K. Mueller, "Is human-animal interaction (HAI) linked to positive youth development? Initial answers,” Appl. Dev. Sci., vol. 18, no. 1, pp. 5-16, 2014.

[6] P. K. Anderson, "A bird in the house: An anthropological perspective on companion parrots," Soc. Anim., vol. 11, no. 4, pp. 393-418, 2003.

[7] D. L. Wells and P. G. Hepper, "Pet ownership and adults' views on the use of animals," Soc. Anim., vol. 5, no. 1, pp. 45-63, 1997.

[8] J. W. Gibbons and M. E. Dorcas, Snakes of the Southeast. University of Georgia Press, 2005.

[9] E. Baharudin, "KONSTRUKSI IDENTITAS KOMUNITAS DERIC (DEPOK REPTILE AMPHIBY COMMUNITY) SECARA ONLINE."

[10] A. F. Saifuddin, "Keluarga dan rumah tangga: Satuan penelitian dalam perubahan masyarakat," Antropol. Indones., 2014.

[11] D. M. Schneider, A Critique of the Study of Kinship. University of Michigan Press, 1984. 
[12] N. Charles and C. A. Davies, "My family and other animals: pets as kin," in Human and Other Animals, Springer, 2011, pp. 69-92.

[13] M. Grandgeorge and M. Hausberger, "Human-animal relationships: from daily life to animal-assisted therapies," Ann. Ist. Super. Sanita, vol. 47, no. 4, pp. 397-408, 2011.

[14] N. Charles, “'Animals just love you as you are': Experiencing kinship across the species barrier," Sociology, vol. 48, no. 4, pp. 715-730, 2014. 